\title{
Experimental characterization of anti-icing system and accretion of re-emitted droplets on turbojet engine blades
}

\author{
G. Linassier, ${ }^{1}$ M. Balland, ${ }^{2}$ \\ SAFRAN Aircraft Engines, F-77550, Moissy-Cramayel, France \\ E. Radenac, ${ }^{3}$ \\ ONERA / DMPE Université de Toulouse, F-31055 Toulouse, France \\ and \\ H. Pervier, ${ }^{4}$ M. Pervier, ${ }^{5}$ and D. Hammond ${ }^{6}$ \\ Cranfield University, College Road, United Kingdom
}

\begin{abstract}
In the framework of STORM, a European project dedicated to icing physics in aircraft engines, a cascade rig representative of an anti-iced engine inlet was tested in icing conditions. This mock-up integrates two rows of vanes, the upstream one being anti-iced using an ElectroThermal Ice Protection System (ET-IPS). Experimental tests were performed to reproduce the following phenomena: runback water and droplet re-emission from anti-iced vanes, and accretion of re-emitted droplets on downstream vanes. A complete experimental database was generated, including the characterization of ice accretion shapes, and the characterization of electro-thermal anti-icing system (power limit for apparition of the runback water or ice accretion). In the current study, these data are compared to droplet trajectory simulation and ice accretion simulation results, for validating icing tools in engine environment. Influence of one-step and multi-step approaches have been investigated.
\end{abstract}

\section{Nomenclature}

$\begin{array}{ll}L W C & =\text { Liquid Water Content }\left(\mathrm{g} \cdot \mathrm{m}^{-3}\right) \\ M V D & =\text { Mean Volumetric Diameter }(\mu \mathrm{m}) \\ (E T)-I P S & =\text { Electro-Thermal) Ice Protection System } \\ T A T & =\text { Total air temperature }\left({ }^{\circ} \mathrm{C}\right) \\ V S V & =\text { Variable Stator Vane } \\ V_{\infty} & =\text { Upstream air velocity }\left(\mathrm{m} \cdot \mathrm{s}^{-1}\right) \\ T & =\text { Ice accretion time }(\mathrm{s}) \\ F E & =\text { Fully evaporative } \\ T C & =\text { Thermocouples } \\ \alpha_{p} & =\text { Liquid Water Concentration }\left(\mathrm{kg} \cdot \mathrm{m}^{-3}\right) \\ \beta & =\text { Droplet catch efficiency }(-)\end{array}$

${ }^{1}$ Aerothermal engineer, Thermal Fluids and Engine Dynamics - Inclement Weather Dept.

${ }^{2}$ Specialist engineer, Head of Inclement Weather Dept.

${ }^{3}$ Research engineer, Aerodynamics and Energetic Modeling Dept., BP 40252 avenue Ed. Belin, Toulouse, France.

${ }^{4}$ Research fellow, Propulsion Engineering Centre.

${ }^{5}$ Research fellow, Propulsion Engineering Centre.

${ }^{6}$ Senior lecturer, Propulsion Engineering Centre. 


\section{Introduction}

Atmospheric icing is an important constraint for the engine manufacturer. During the different flight phases, the engine can be exposed to severe icing conditions from concentrated cloud composed of super-cooled droplets. When these droplets collide with surfaces, ice accretion occurs on engine air intake, spinner, inlet fan blades and booster blades. Operability of the engine can be impacted through different ways: stall, flameout, mechanical damages caused by ice shedding.

To ensure the engine can be safely operated under icing conditions, propulsion systems are equipped with Ice Protection Systems, which are mostly based on air-heated technology through engine bled offs. Depending on the requirements, these systems can be either "fully evaporative" or "running wet". In the latter case, runback water will flow downstream the heated area. For some anti-iced components like engine vanes, struts or probes, if the surface is warm enough, runback water can either peel off under the action of the aerodynamic shear stresses, or accumulate at the trailing edge before shedding into the air flow. Liquid water will be atomized in droplets that can impinge on nonprotected area, located downstream into the flow path, and create ice. Some models are proposed for the modeling of this phenomena [1] [2], but there is a lack of data for validation on representative industrial test cases.

Experimental studies have been dedicated to build experimental database for the validation of anti-icing numerical tools, with a focus on airframe application. Al-Khalil et al. [3] have tested a NACA0012 airfoil with an electro-thermal ice protection system. Power density, surface temperature and shape of runback ice beyond the heated region are characterized. Similar experiment was performed by Papadakis et al. [4] with a business jet airfoil equipped with a bleed air anti-icing system.

For engine vanes application, experimental database for tools validation are less numerous. Some work have been dedicated to the analysis of aerodynamic performance degradation caused by icing on engine compressor blades. Lee et al. [5] have computed ice accretion shape for stage 67A type stator, and Ramezanizadeh et al. [6] have used replicate of the computed ice shape to experimentally characterize the degradation of aerodynamic performance. Other studies have been dedicated to the characterization of thermal anti-icing systems for engine vanes. Shires et al. [7] have performed experiment with an anti-ice cascade vanes (both electro-thermal and hot air anti-icing system were tested). Dong et al. have tested a sector of five guide vanes, equipped with a hot air anti-icing system [8], and more recently, an engine strut anti-icing system using hot lubricating oil [9]. Tatar et al [10] also investigated experimentally the efficiency of a hot air anti-icing system for a stator vane.

Previous works provided material to validate modeling of different thermal anti-icing technologies Ice Protection System (anti-icing power limit, characterization of surface temperature...). However, to our knowledge, there is no published database dealing with the phenomena of water runback and droplet re-emission for anti-iced vanes.

The objective of this study is to build an experimental database for the validation of icing tools applied for engine applications, more specifically for the modeling of thermal Ice Protection System. For this purpose, a cascade rig, reproducing the first stages of an engine inlet with anti-iced vanes, have been manufactured and tested into an Icing Wind Tunnel. The experiment has been designed to simulate conditions with water runback and accretion caused by re-impingement on unheated components. Additionally to this experimental work, numerical simulation of some test cases have been performed. In this study, the numerical modeling had been on the modeling of ice accretion on the first stage, without anti-icing and only with direct impingement.

\section{Experimental apparatus}

The cascade rig is a structure representative of the first stage of a compressor, and is composed of two rows of aluminum blades. The first row is composed of six stator vanes which have a fixed angle of attack of zero degree. This row of blade can be translated left/right and upstream/downstream by a few centimeters in order to change the alignment and/or the gap with respect to the second row of blades. The second row is composed of six VSVs (Variable Stator Vane) whose angle of attack can be modified from 0 to approximately 50 degrees. It is also possible to remove the VSVs from the test section. The order of magnitude for the chord length of the anti-iced vane and the VSV chords is approximately $5 \mathrm{~cm}$. A view of the cascade rig blades is available on Fig. 1 and 2 . 

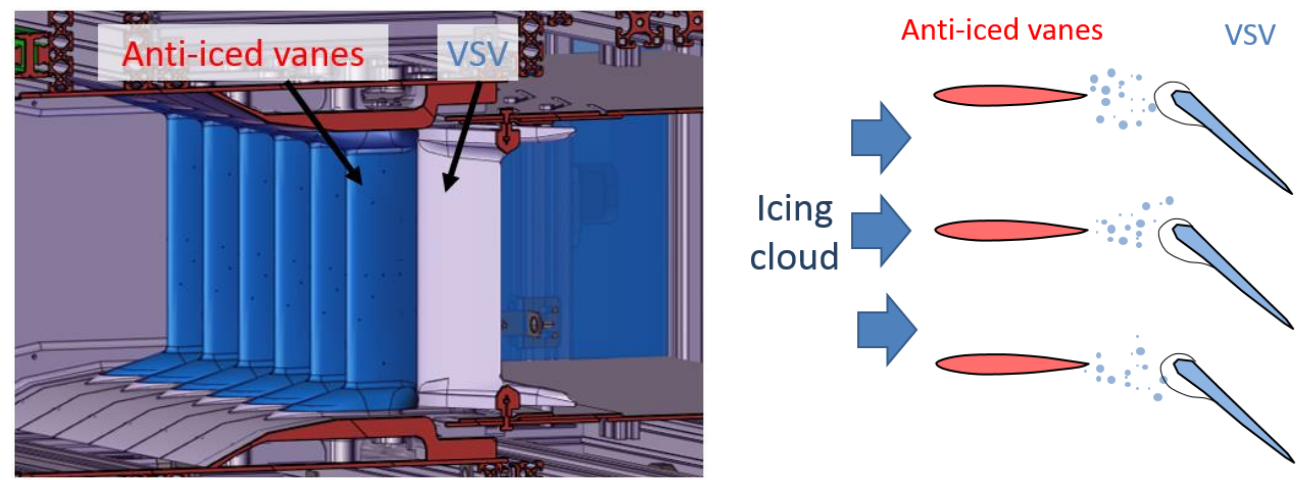

Fig. 1 Views of the cascade rig experiment (left: CAD file; right: sketch of the grid with droplet re-emission)

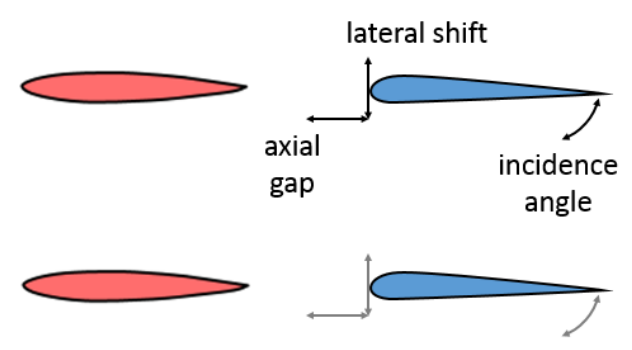

(a) No incidence, VSV and vanes aligned

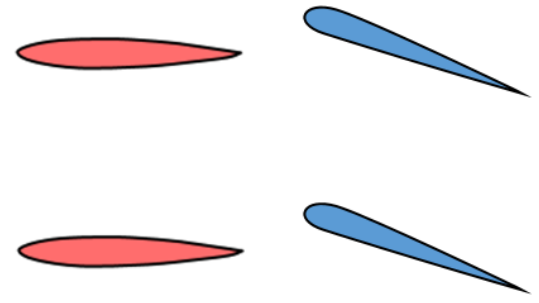

(b) VSV with incidence, VSV and vanes unaligned

Fig. 2 Sketch of the VSV position setting

Anti-iced vanes are designed as hollow components, with four heater mats embedded on the wall inner side (B and $\mathrm{A}$ on pressure side, $\mathrm{C}$ and D on suction side, see Fig. 3). Four power supply units are used to control the heater mats, each one is connected to the same heaters for the six struts (A, B, C or D). It is possible to control independently the heat power for each area. Each mats can deliver a maximum heat flux of the order of a few W.cm .

To manage the integration of these heater mats into the component, the vanes were designed as two separate half shells, mechanically assembled. Due to the design limitation, it was not possible to achieve a perfectly symmetric geometry. The interface between the two shells is not located exactly at the leading edge, and it will generate a small thermal resistance. To compensate this dissymmetry, the power input on heat mat B is compensated to heat efficiently the leading edge, and obtain a temperature profile as symmetrical as possible for the two sides of the vanes.

The vanes are instrumented with thermocouples and pressure taps to characterize wall temperature and static pressure. Thermocouples are embedded into the blade walls, and located at mid-height on leading edge (x1), and all along the chord wise direction on both intrados (x3) and extrados (x3).

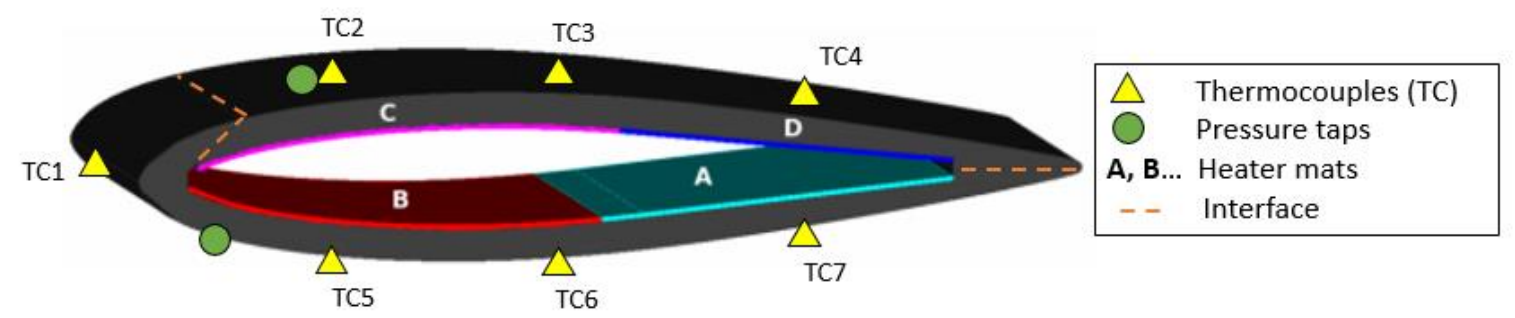

Fig. 3 Sectional view of the strut with the heater mats and thermocouples (mid-height)

The mock-up has been installed and tested into the Cranfield University Icing-Wind-Tunnel (see Fig. 4). This facility is a closed-loop wind tunnel with capability to reproduce atmospheric icing conditions (air temperature down to $-26^{\circ} \mathrm{C}$, LWC range between 0.20 and $7 \mathrm{~g} / \mathrm{m}^{3}$, droplet size ranges between 15 and $80 \mu \mathrm{m}$ ). The facility operates at ambient pressure (no altitude effects). 


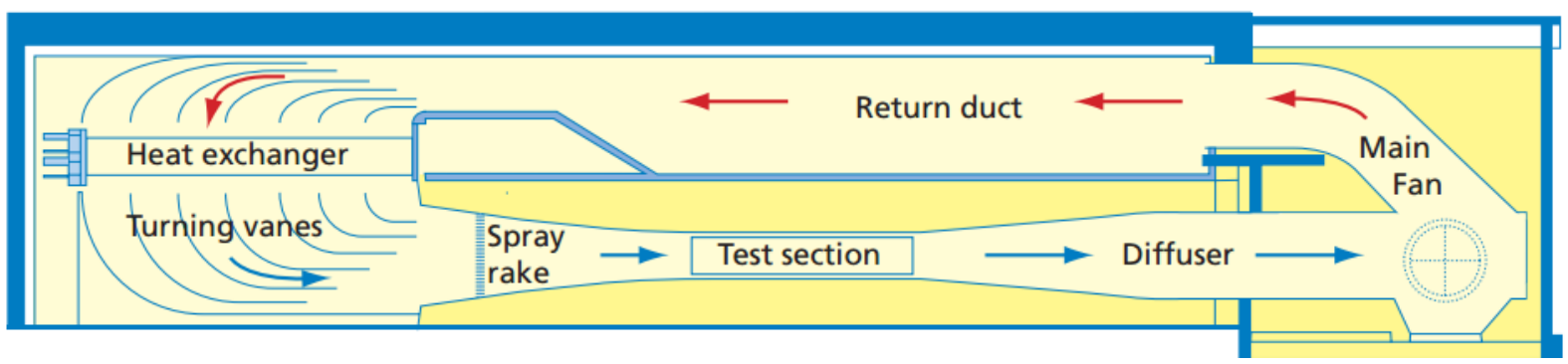

Fig. 4 Side view of Cranfield University IWT

Optical accesses are available on left and right side of the test section, allowing the direct visualization of the test specimen. Two video cameras are used to record the test sequence: one is dedicated to monitor the anti-iced vanes leading edge, the second to monitor the presence of liquid water rivulets at the trailing edge.

The characterization of the ice accretion shape is done by manually drawing a 2D imprint. To facilitate this process, the test specimen is mounted on a drawer that can be extracted from the test vein quickly after the end of a run. In order to minimize the influence of side walls, all analysis is focused on the vanes at the middle of the test section (vanes number 3 and 4).

\section{Test protocol}

\section{A. Calibration tests}

Calibration tests have been performed to ensure cloud conditions are as close as possible to the target value. The measurement of the tunnel air velocity is achieved using an average of two pressure tapings, which is calibrated using a pitot/static measurement in front of the struts. A calibration of the icing cloud was also performed, to ensure the correct LWC and a good homogeneity around the area of interest. LWC measurement was achieved by measuring the ice thickness in rime ice conditions on a calibration blade. The LWC is then deduced from the ice thickness, density, accretion time and tunnel velocity. The calibration blade is inserted $5 \mathrm{~cm}$ downstream of the struts, at 3 different heights, to achieve a mapping of the LWC. For test conditions presented into this current study, around the middle struts, target LWC is reached with $+/-20 \%$ discrepancy.

\section{B. Test objectives and configurations}

In order to build a comprehensive database for ice accretion tools validation, different types of tests have been performed.

The first step was to characterize the ice accretion shape on the first vanes row for different icing conditions, without action of the anti-icing system. The VSV row is removed, to avoid additional pressure loss caused by ice accretion on this stage. The tunnel air velocity is regulated and kept constant, as reproducing air velocity variation during ice accretion add some complexity to the numerical simulation.

The second step was to identify the thermal power limit to observe "fully evaporative state" (FE, transition from dry state to apparition of liquid water at trailing edge) and "running wet state" (RW, formation of ice on the surface) on the heated vanes. To achieve that, variations of the power of the heater mats are performed during one run, until the transition to one state to another occur. The power limits are identified by monitoring the water state at the leading edge and the trailing edge. Tests are also performed without VSV.

Finally, the VSVs are installed, and the anti-icing heat power heat power is set to observe water runback, leading to droplet re-emission and accretion on VSVs. Tests are performed for different settings of the VSV geometry (incidence, alignment) and heat power (more or less close to the identified FE or RW limit).

\section{Test matrix}

The test matrix icing conditions are representative of appendix $\mathrm{C}$ icing conditions. The air flow parameters have been set in order to reproduce realistic conditions for engine inlet for two different regimes. Two air velocities have

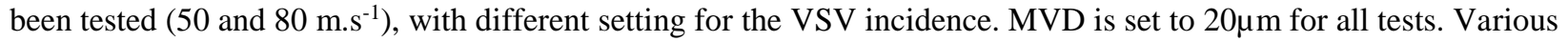
TAT (down to $-20^{\circ} \mathrm{C}$ ) and LWC $\left(0.3\right.$ to $\left.1.75 \mathrm{~g} . \mathrm{m}^{-3}\right)$ have been tested, to cover both glaze and rime ice conditions. This 
paper will focus on the description of results obtained for the icing conditions summarized into the following table. The value V.LWC is provided to give an estimation of the water flow rate injected during the tests.

\begin{tabular}{|c|c|c|c|c|c|}
\hline $\begin{array}{c}\text { Test } \\
\text { condition }\end{array}$ & $\begin{array}{c}\text { TAT } \\
\left({ }^{\circ} \mathrm{C}\right)\end{array}$ & $\begin{array}{c}\text { Air velocity } \\
\left(\mathrm{m} \cdot \mathrm{s}^{-1}\right)\end{array}$ & $\begin{array}{c}\text { LWC } \\
\left(\mathrm{g} \cdot \mathrm{m}^{-3}\right)\end{array}$ & $\begin{array}{c}\text { Type of } \\
\text { ice }\end{array}$ & $\begin{array}{c}\text { LWC.V } \\
\left(\mathrm{g} \cdot \mathrm{m}^{-2} \cdot \mathrm{s}^{-1}\right)\end{array}$ \\
\hline 2 & -5 & 50 & 0.60 & glaze & 30 \\
\hline 3 & -5 & 80 & 0.60 & glaze & 48 \\
\hline 5 & -5 & 50 & 1.75 & glaze & 88 \\
\hline 8 & -20 & 50 & 1.00 & rime & 50 \\
\hline 9 & -20 & 80 & 1.00 & rime & 80 \\
\hline
\end{tabular}

\section{Experimental results and analysis}

\section{A. Ice accretion on vanes}

An example of visualization of ice accretion is available on Fig. 5, for typical glaze ice conditions. After each tests, two imprints of the ice shape are taken on the two middle struts, at approximately $50 \%$ height. The air flow incidence being null, ice accretion occurs only at the vanes leading edge. The ice shape can be characterized by both its width (related to the flow obstruction) and its chord-wise extent. It can be noticed that shedding events never occurred during the different tests.

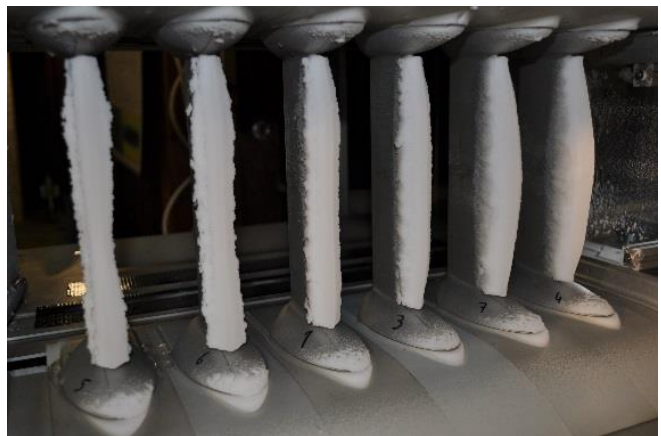

(a) Test condition 8

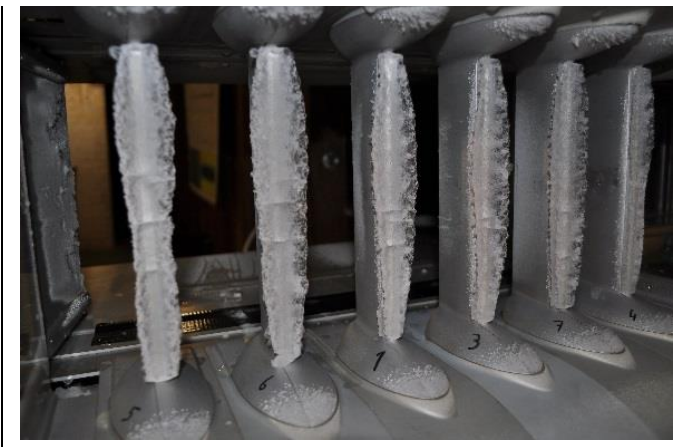

(b) Test condition 3

Fig. 5 View of the cascade rig with ice accretion on vanes.

Fig. 6 presents two examples of ice shape. First one (test condition 8) is representative of typical rime ice conditions (accretion time $\mathrm{t}=600 \mathrm{~s}$ ), with a spearhead shape, while the second is a glaze ice type (accretion time $\mathrm{t}=300 \mathrm{~s}$ ), with a triangular shape. For these two tests conditions, it can be seen that the ice accretion shape on both middle struts are similar, assessing of the homogeneity of the air velocity and water concentration. For the glaze ice case, the obstruction is slightly more important than for the rime ice condition, even if the water injected is doubled in the rime ice condition (LWC. $V_{\infty}$ is similar for both cases, but the ice accretion time is doubled).

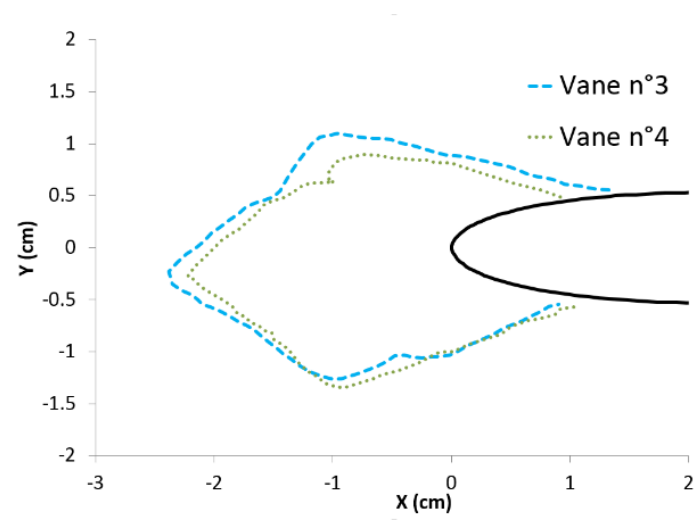

(a) Test condition $8 ; \mathrm{T}=600 \mathrm{~s}$

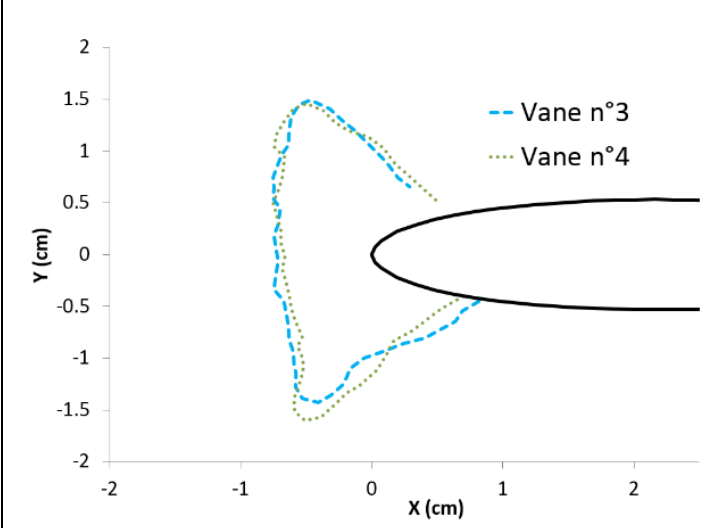

(b) Test condition 3; $\mathrm{T}=300 \mathrm{~s}$ 
Fig. 6 Experimental ice shape for vanes (anti-icing off).

\section{B. Characterization of ET-IPS power limits}

For a given icing condition, an influence on the heat power had been first performed to characterize the vane temperature at different power setting. Then, the research for the FE and RW power limit was performed during the same run, starting at higher power with the FE limit.

The FE limit was reached for test condition 3. The minimum power required for FE and RW state are compared in the following table, with a factor of 5 to 7 for the different heater mats. For test condition 5, 8 and 9, despite starting the tests at maximum heat power, it was not possible to reach the FE limit, due to higher water concentration (condition 5) or much lower air temperature (conditions 8 and 9). For test condition 2, the FE limit was not characterized, but it is assumed to be at similar level than for test condition 3 .

\begin{tabular}{|c|c|c|c|c|}
\hline \multirow{2}{*}{$\begin{array}{c}\text { Test } \\
\text { condition 3 }\end{array}$} & \multicolumn{4}{|c|}{ Heater mats power (Watts) } \\
\cline { 2 - 5 } & $\mathrm{B}$ & $\mathrm{C}$ & $\mathrm{D}$ & $\mathrm{A}$ \\
\hline RW & 217 & 96 & 97 & 54 \\
\hline FE & 1008 & 718 & 486 & 380 \\
\hline
\end{tabular}

Fig. 7 summarizes the level of heat flux required to achieve running wet state for the difference icing conditions tested. The anti-icing limit appears to be mainly fixed by the heat power on the heater B, located on the half shell that includes the leading edge. The heat power is low for rearwards mats, where the convective heat transfer is reduced compared to the upstream part of the vane. For test conditions 2, 3 and 5 (glaze ice cases), the anti-icing power limit is rather similar, and is achieved with $15-20 \%$ of the heater B max power. For test conditions 8 and 9 (rime ice cases), due to lower air temperature, the heat power required is significantly higher (respectively $33 \%$ and $55 \%$ on heater B). The increase of the upstream air velocity from 50 to $80 \mathrm{~m} \cdot \mathrm{s}^{-1}$ has also a noticeable influence on the running wet limit, by increasing the convective heat transfer and the impinging water flow rate.

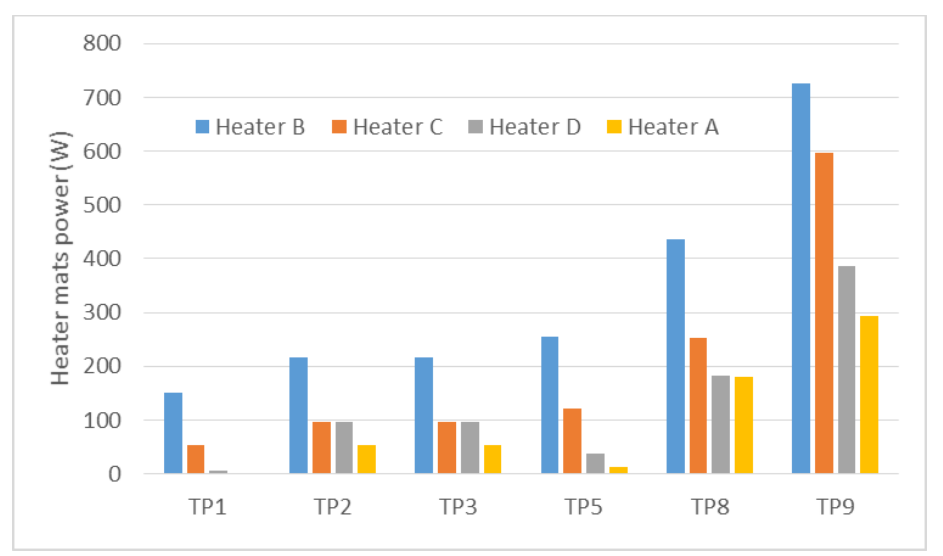

Fig. 7 Heat power required to achieve running wet limit on vanes for different test conditions

Fig. 8 presents an example of temperature evolution for test condition 3, for the thermocouples located close to the trailing edge and the leading edge. For this test condition, the fully evaporative limit is characterized by maximum wall temperature above $30^{\circ} \mathrm{C}$, while for running wet state, the wall temperature has only to be kept above the water freezing point. The dissymmetry of the temperature between the upper (TCs 2 and 5) and lower shells (TCs 4 and 7) can be observed. It will depend on the power setting, but generally, the discrepancies are more noticeable close to the leading edge, with a temperature gap around $10^{\circ} \mathrm{C}$. 


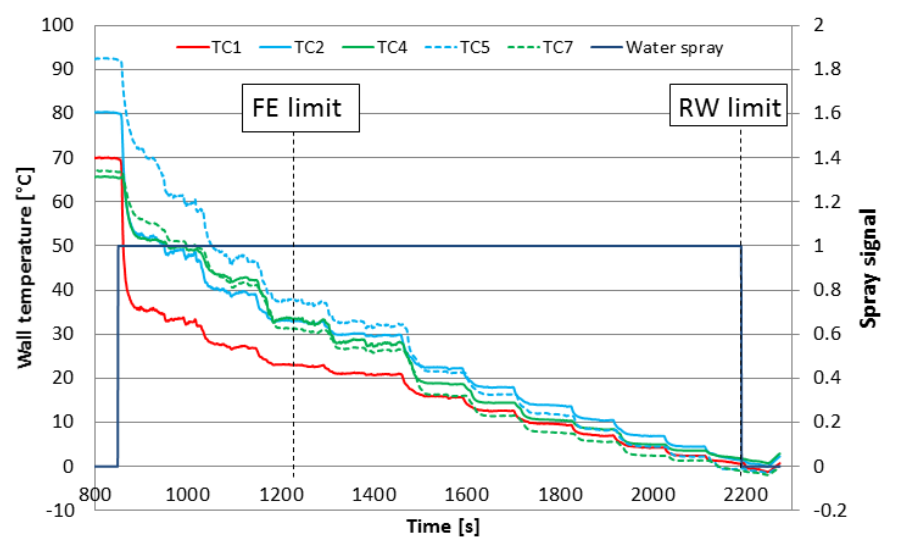

Fig. 8 Wall temperature evolution with heat power variation during water injection (test condition 3)

\section{Characterization of droplet re-emission phenomena}

With this last part of the test campaign, the influence of the VSV geometric settings and of the vane anti-icing power on the VSV ice accretion has been thoroughly investigated. First, the influence of the alignment of the VSV has been tested. For test condition 8 (see Fig. 9), the VSV incidence was set to $9^{\circ}$, and two tests were performed, with the VSV leading edge being aligned (8-a) and unaligned (8-b) with the anti-iced vanes. In both conditions, the vane heat power is set to achieve running wet state (set to approximately twice the running wet limit value).

In the first situation (8-a), a small ice cap is observed on the leading edge, while in the second situation (8-b), the ice shape is very quickly growing forward. Most probable explanation is that, with the VSV aligned, the ice accretion is caused exclusively by the impingement of re-emitted droplets, the leading edge being shielded from direct impingement by the upstream vane. Because of the incidence of the VSV, ice is also forming on the trailing edge, but only for the case with VSV aligned. As illustrated below, the ice shape is growing with a feather-like shape, oriented with the flow. This feature is not correctly captured with the 2D tracing method. From the picture, the actual interface between the ice and the vane surface is limited to approximately $2 \mathrm{~cm}$. From the two imprints and the pictures, it was observed that the ice accretion at 50\% height increase from VSV 1 to VSV 4.

For the case (8-a), the ice on the leading edge seems to be more irregular than the one observed from direct impingement. Another interesting feature is that the ice shape presents some local lobes. The presence of these lobes indicates that locally, the ice thickness becomes high enough to allow collecting droplets from direct impingement, accelerating the ice growth.

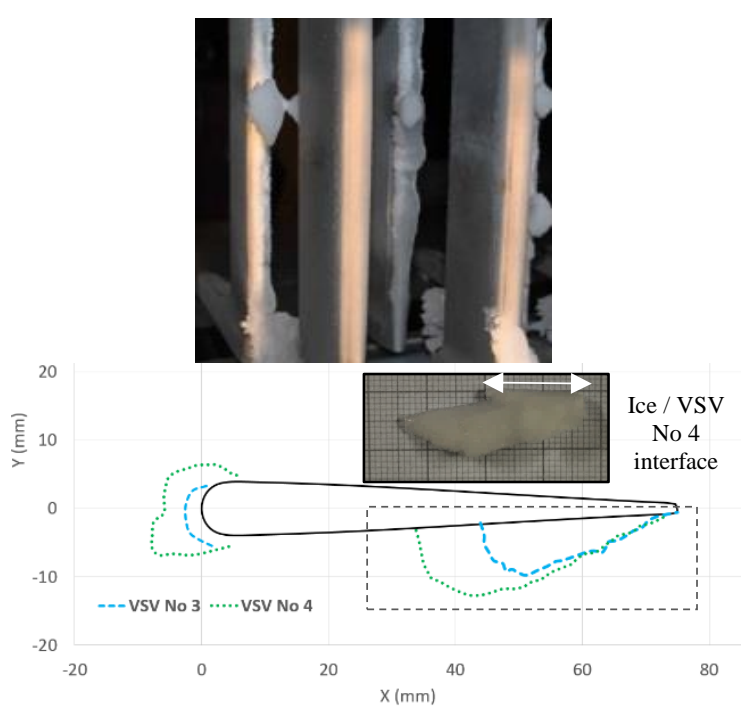

(a) Test $(8-\mathrm{a}) ; \mathrm{T}=10 \mathrm{~min}$
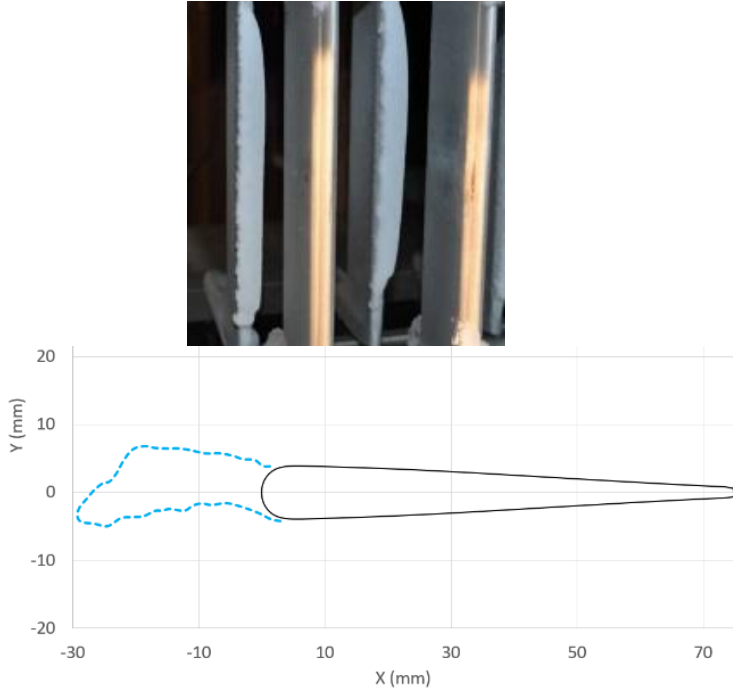

(b) Test (8-b); $\mathrm{T}=5 \mathrm{~min}$

Fig. 9 Ice accretion on VSV for test condition 8 (influence of VSV alignment with vanes) 
The influence of the heat power on the VSV ice accretion has been investigated for several test conditions. For these tests, the VSV incidence was set to $0^{\circ}$, in order to avoid ice accretion on the trailing edge, and the VSV aligned with the anti-iced vanes. The heat power was set more or less close to the RW or FE limit. For test condition 2, even if the FE limit was not characterized, it was assumed its value is the same order of magnitude as for test condition 3.

\begin{tabular}{|c|c|c|c|c|c|c|}
\hline \multirow{2}{*}{$\begin{array}{c}\text { Test } \\
\text { condition }\end{array}$} & Accretion & \multicolumn{5}{|c|}{ Heater mats power (Watts) } \\
\cline { 3 - 7 } & time (min) & B & C & D & A & Comments \\
\hline 2-a & 10 & 254 & 121 & 122 & 73 & Close to RW limit \\
\hline 2-b & 10 & 486 & 293 & 150 & 96 & Between FE - RW limit \\
\hline 2-c & 10 & 998 & 713 & 482 & 378 & Above FE limit \\
\hline 3-a & 7 & 217 & 96 & 70 & 96 & Close to RW limit \\
\hline 3-b & 10 & 925 & 652 & 432 & 334 & Close FE limit \\
\hline 9-a & 5 & 722 & 496 & 383 & 292 & Close to RW limit \\
\hline 9-b & 5 & 1325 & 829 & 598 & 480 & $\sim 1.7$ x RW limit \\
\hline
\end{tabular}

The heat power has a clear impact on the quantity of ice accreted on leading edge. For test (2-b), the ice layer is too thin to be characterized properly, and for test (2-c), there is no ice at all. It confirms the observation that, in this situation, only re-emitted droplets impinge on the VSV leading edge and contribute to the ice formation. Ice accretion was characterized only for test condition (2-a) and is presented on Fig. 10. The ice has a very rounded ice shape, with a rather irregular ice shape along the span wise direction.

Similar results are observed for test condition 3 and 9 . For test (3-a), the quantity of ice is significantly more important than for (3-b), but the ice shape is also skewed toward the upper side of the profile, despite the geometry being symmetrical (see Fig. 11). All along the span wise, ice accretion on the upper side is probably caused by direct impingement, as soon as the ice thickness reaches some critical value. The ice accretion time is shortened to $7 \mathrm{~min}$, due to the fast increase of the ice blockage. Compared to test (2-a), which is also performed with heat power close to the RW limit, it is interesting to notice that the increase of the air flow velocity have a major influence of the flow obstruction.

For test condition 9, the increase of the heat power significantly decreases the chord wise extent of the ice accretion shape (see Fig. 12). Compared to test (3-a), the ice shape remains narrower, and the effect of blockage remains limited. This is probably due to the limitation of the ice accretion time to $5 \mathrm{~min}$, but also to the colder temperature.
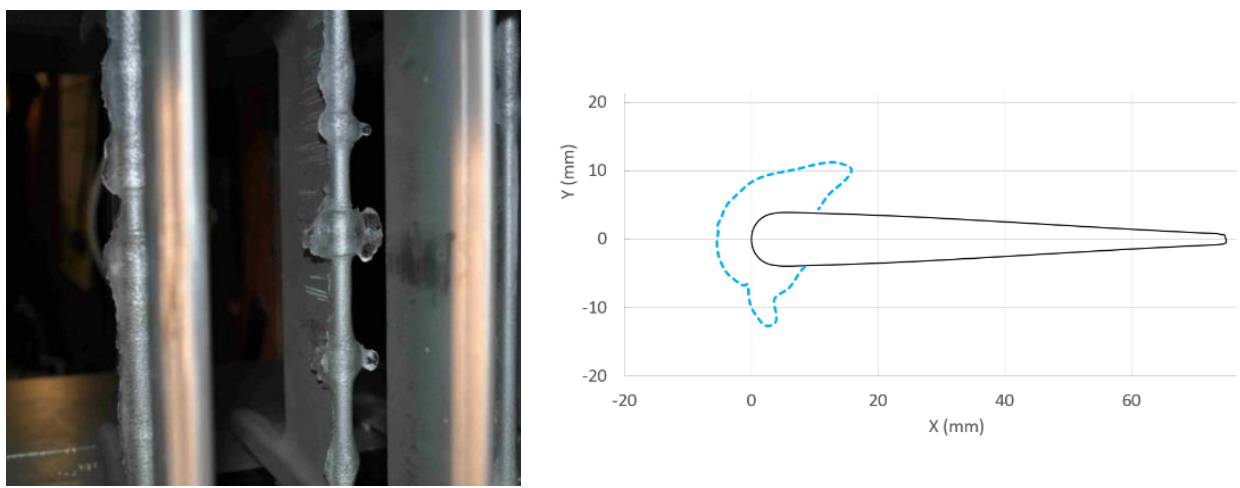

Fig. 10 Ice accretion on VSV for test condition (2-a); T=10min 


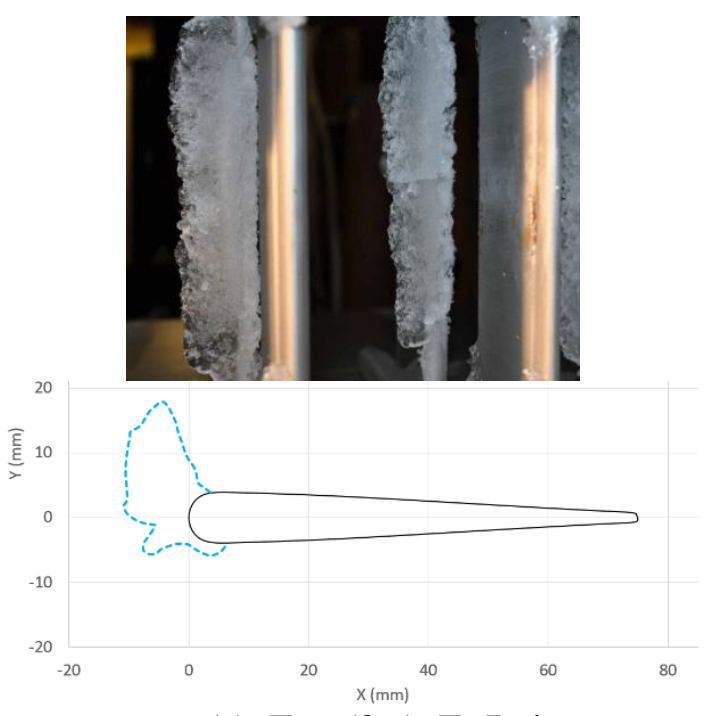

(a) Test (3-a); $\mathrm{T}=7 \mathrm{~min}$

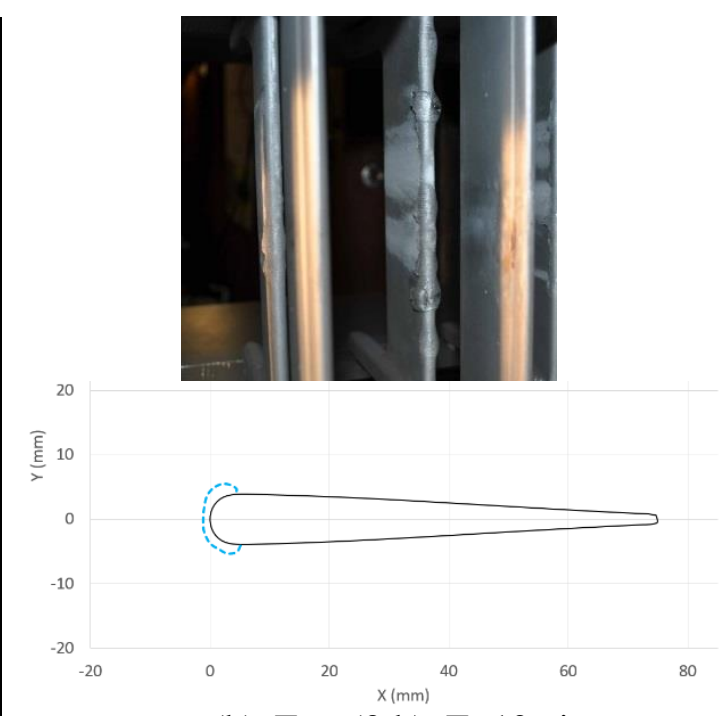

(b) Test (3-b); $\mathrm{T}=10 \mathrm{~min}$

Fig. 11 Ice accretion on VSV for test condition 3 (influence of vanes heating power)

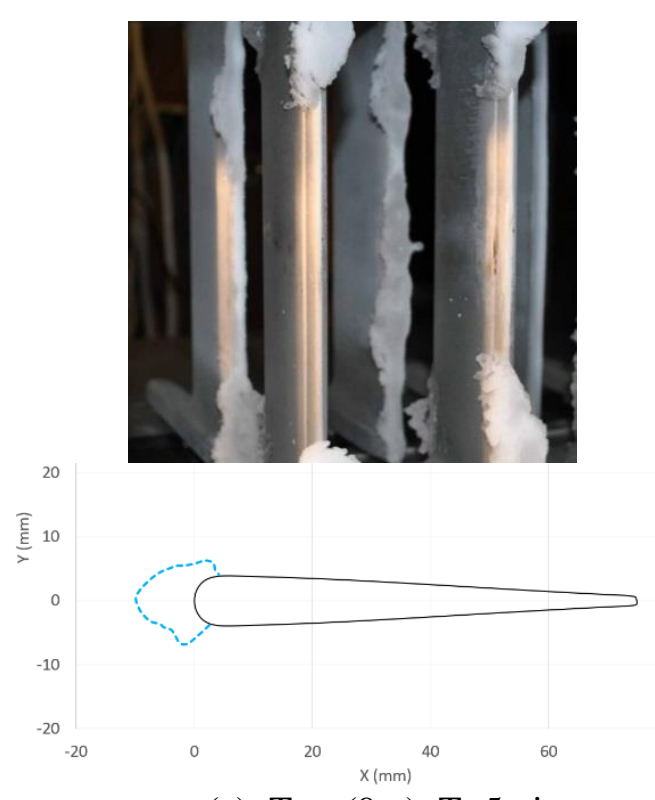

(a) Test (9-a); $\mathrm{T}=5 \mathrm{~min}$

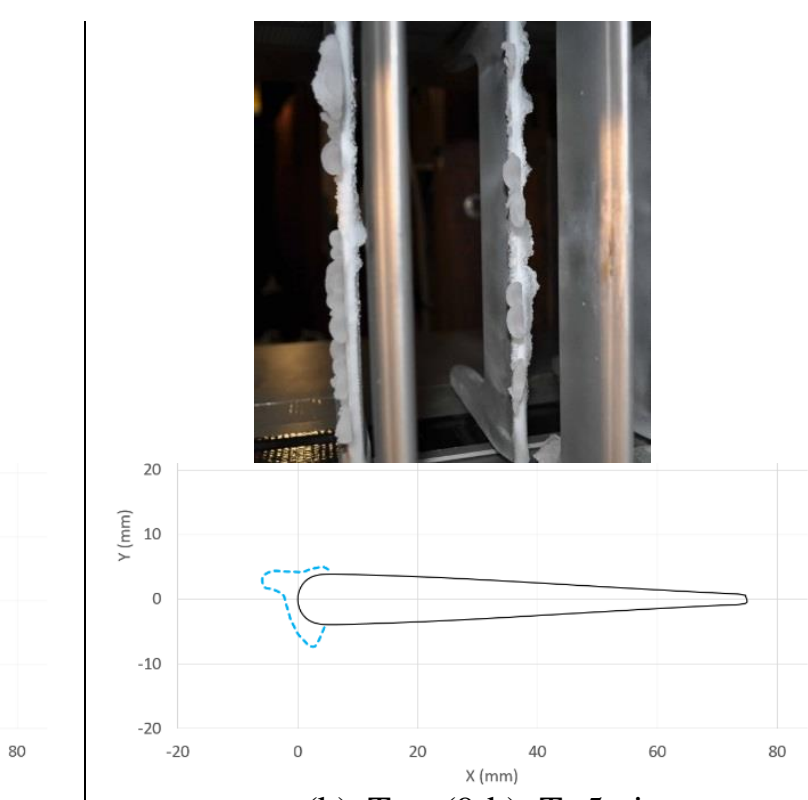

(b) Test (9-b); $\mathrm{T}=5 \mathrm{~min}$

Fig. 12 Ice accretion on VSV for test condition 9 (influence of vanes heating power)

Some observations of the water on the anti-iced vane trailing edge have been performed. The Fig. 13 and 14 provides an overview of the phenomena. Depending on the test conditions, the water is flowing as rivulets or beads (or a mix of both), and accumulates at the trailing edge to create some reservoirs. The water droplets are released from these reservoirs under the action of the airflow shear stress. These reservoirs can be more or less uniformly distributed along the span wise direction, and their size can also evolve. Additional work is required to establish correlations between the test conditions, heat power, and the presence of water beads and or rivulets.

These phenomena may be linked to the irregular ice shapes observed on the VSV leading edge, and also to the presence or not of lobe. As the water droplets will be re-emitted from these reservoirs, their distribution may be linked to the local increase of ice thickness previously observed. 


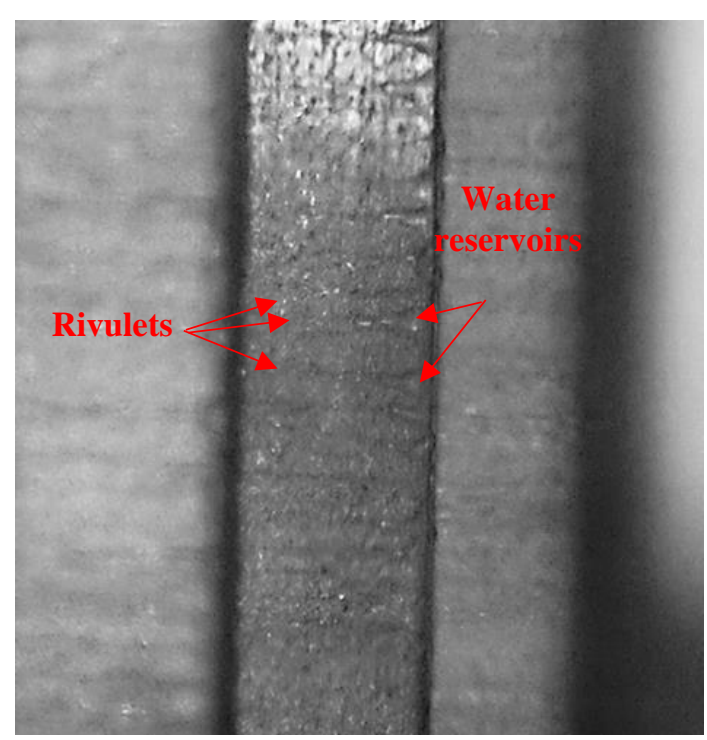

Fig. 13 Visualization of the anti-iced vanes trailing edge for tests (3-a)

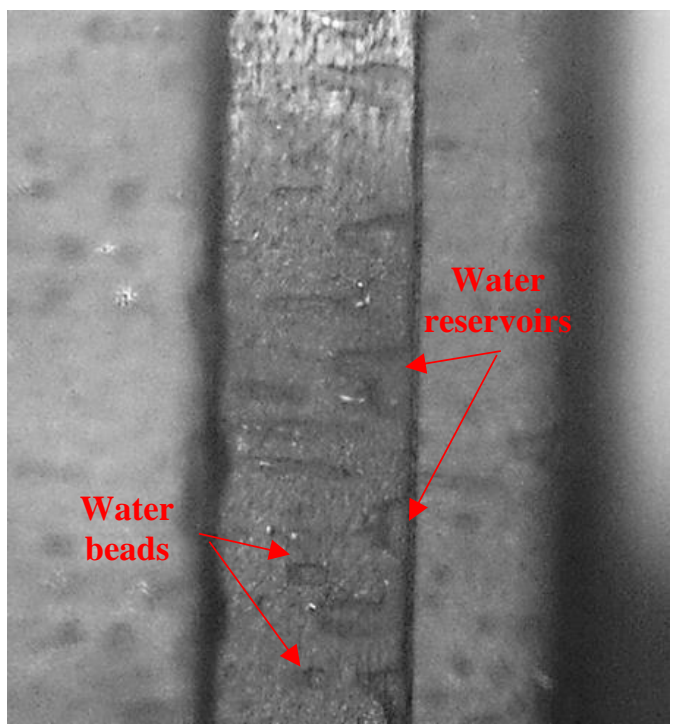

Fig. 14 Visualization of the anti-iced vanes trailing edge for test (2-b)

Additional tests have been performed with different settings for the VSV incidence. As seen on Fig. 9, for test (8a), an incidence of $10^{\circ}$ leads to accretion on the trailing edge of the VSV, with the extent of the iced area being approximately $3 \mathrm{~cm}$. Same observations were pointed out for other test conditions, with an increase of the extent of the iced area with an increase of the incidence angle.

\begin{tabular}{|c|c|c|c|c|c|}
\hline $\begin{array}{c}\text { Test } \\
\text { condition }\end{array}$ & $\begin{array}{l}\text { Accretion } \\
\text { time (min) }\end{array}$ & $\begin{array}{l}\text { Air velocity } \\
\left(\mathbf{m} . \mathrm{s}^{-1}\right)\end{array}$ & Heater mats power & $\begin{array}{c}\text { VSV } \\
\text { incidence }\left({ }^{\circ}\right)\end{array}$ & $\begin{array}{l}\text { Extent of iced area } \\
\text { on pressure side }\end{array}$ \\
\hline $2-d$ & 10 & 50 & \multirow{2}{*}{$\begin{array}{c}\text { Same as 2-a } \\
\text { (close to RW limit) }\end{array}$} & 9 & Small ridge \\
\hline 2 -e & 3 & 50 & & 48 & $5 \mathrm{~cm}$ \\
\hline $3-\mathrm{c}$ & 5 & 80 & \multirow{2}{*}{$\begin{array}{c}\text { Same as 3-a } \\
\text { (close to RW limit) }\end{array}$} & 9 & Small ridge \\
\hline $3-d$ & 3 & 80 & & 25 & $7 \mathrm{~cm}$ \\
\hline
\end{tabular}

For both test conditions (2-d) and (3-c), with $10^{\circ}$ incidence, only a small ridge of ice is observed on the trailing edge of some of the VSVs, and no print of ice were taken. For test conditions (2-e) and (3-d), the extent of the iced 
area is more important as can be seen on Fig. 15 and 16 . For $25^{\circ}$ incidence, the extent of the iced area is approximately $5 \mathrm{~cm}$, while with $48^{\circ}$ incidence, the pressure side is nearly entirely covered with ice.

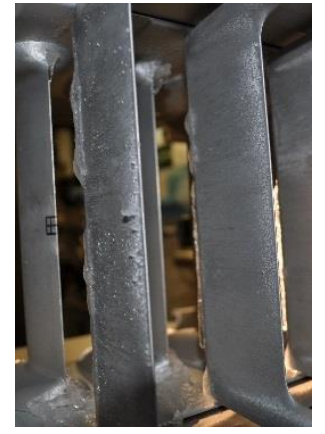

(a) Test (2-d); T=10min; rear view

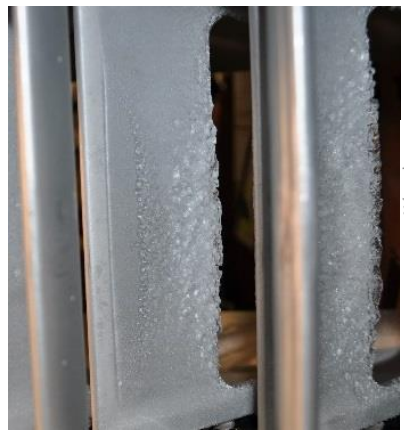

(b) Test (2-e); T=3min; front view and print

Fig. 15 Ice accretion on VSV for test condition 2 (influence of VSV incidence)

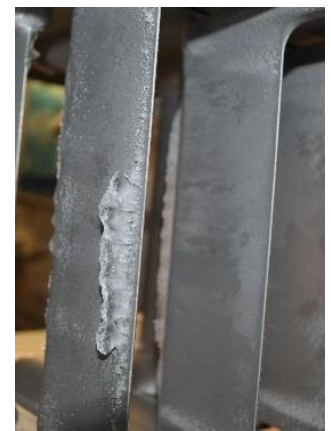

(a) Test (3-c); $\mathrm{T}=5 \mathrm{~min}$; rear view
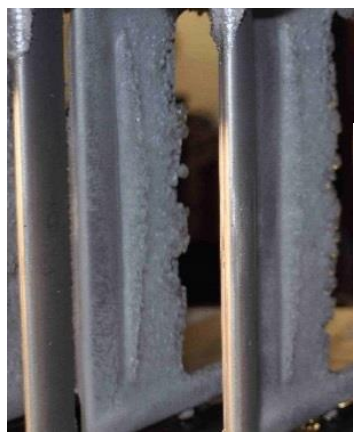

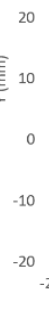

(b) Test (3-d); T=3min; front view and print

Fig. 16 Ice accretion on VSV for test condition 3 (influence of VSV incidence)

\section{Numerical analysis and results}

\section{A. Numerical approach}

The modeling of ice accretion requires a multi-physic simulation (modeling of the airflow, droplet trajectories and thermal/mass balance for the liquid film at the surface). For the present study, numerical analysis of droplet trajectory on the complete test article is modelled using the CEDRE code [11]. The gas flow is calculated using an inviscid approach, and the droplet trajectory an Eulerian approach. The mock-up geometry is simplified, and modeled as a 2D one. The computational domain introduces both vanes stages, and the different ducts channeling the flow upstream and downstream. The water droplet are injected upstream with a uniform concentration and a monodisperse size distribution. As the calculation were performed in parallel to the cascade rig design and manufacturing, it has to be noticed that the modeled VSV incidence is $10^{\circ}$ instead of the actual value of $9^{\circ}$, that was characterized on the final mock-up afterwards.

Ice accretion simulation on the first vane stage is performed using the IGLOO2D icing suite [12]. This numerical tool integrates several solver that can be used for the different phase of the calculation (see Fig. 17). The air flow is calculated using a solver based on the Euler equations, with the heat transfer calculated with an integral boundary layer approach. The droplet trajectories are calculated using an Eulerian approach. Finally, ice accretion is calculated using a solver based on the Messinger approach.

This Messinger solver can be run with either "predictor", "predictor-corrector" approach or "multi-step approach". Predictor corresponds to one-step ice accretion calculation. In "predictor-corrector" mode, two loops are made, one for the clean profile (predictor) and the second on an iced profile with an updated grid (corrector). The corrector step enables to account for the influence of the predictor ice shape on the airflow and droplet trajectories. In multi-step 
approach, the calculation is iteratively performed in $\mathrm{N}$ steps with an update of the profile shape with the progressive building of the ice. For the ice accretion calculation, the geometry of the cascade rig is simplified.

To reproduce the airflow at the middle of the test vein, the computational domain is assumed to be 2D periodic. The mesh is automatically generated by the IGLOO2D meshing tools, and updated at each step to fit the growing ice shape.

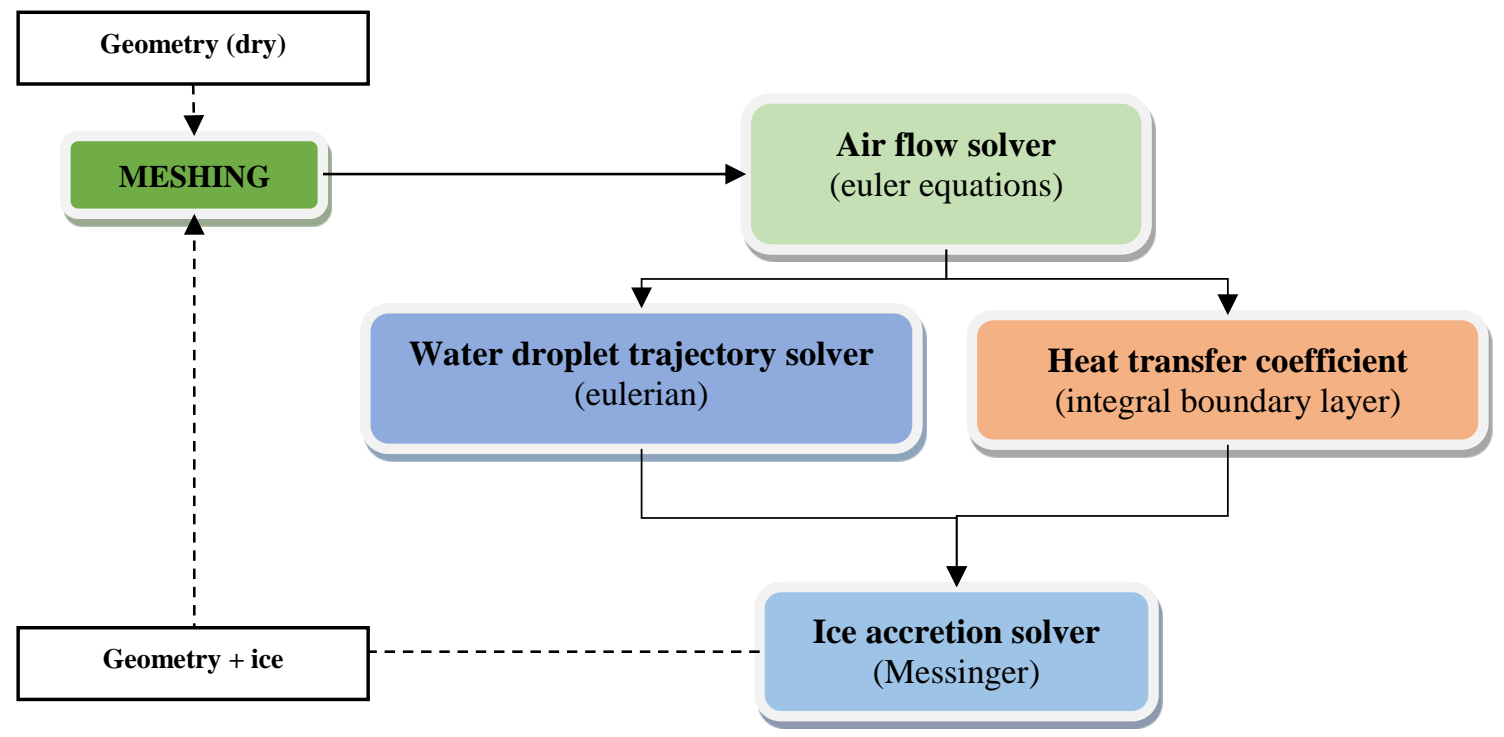

Fig. 17 General description of the IGLOO2D solver

\section{B. Results}

As previously explained, the numerical analysis was at this stage limited to the modeling of droplet trajectory and ice accretion on the first stator stage, without anti-icing. For air velocity $50 \mathrm{~m} / \mathrm{s}$, the water droplet concentration and catch efficiency are presented on Fig. 18. It can be noticed that the water concentration is rather homogeneous at the center vein, but higher value are observed on the side. In the calculation, water is injected upstream with a uniform concentration, and the inhomogeneity of the water concentration is caused by the presence a non-symmetric convergent upstream the cascade rig.

As the droplet re-emission from the vane is not modelled, the shadowing effect of the vane stage can be clearly observed on the simulation. The impingement of the droplets on VSVs only occurs on the pressure side, with an impingement efficiency increasing from VSV 1 to 4 . These observations are in line with the tendencies observed for test conditions (8-a) on Fig. 9. It has also to be noticed that the maximum level of water catch efficiency is very low (below 0.1). As it is a typical rime ice case, the impingement area is identical to the ice and VSV interface, corresponding to approximately the last $2 \mathrm{~cm}$ of the profile. On Fig. 18, it can be noticed that the extent of the impingement area from calculation can cover the complete pressure side for on VSVs 5 and 4. Improvement of the results may be possible, for example by using a Navier-Stokes approach and modeling a polydisperse size distribution. 


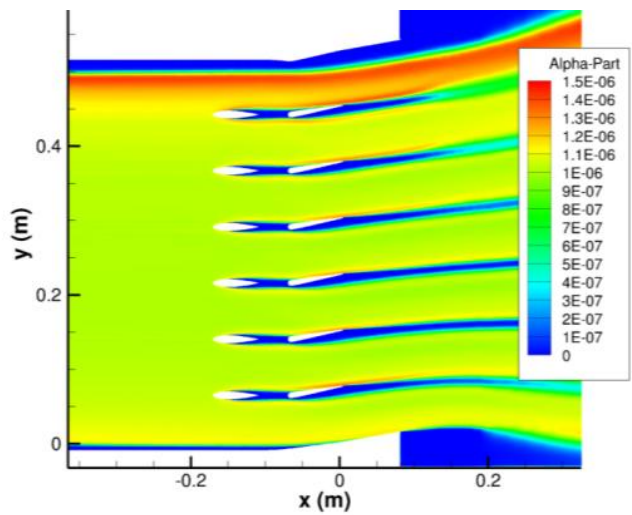

(a) Liquid water concentration

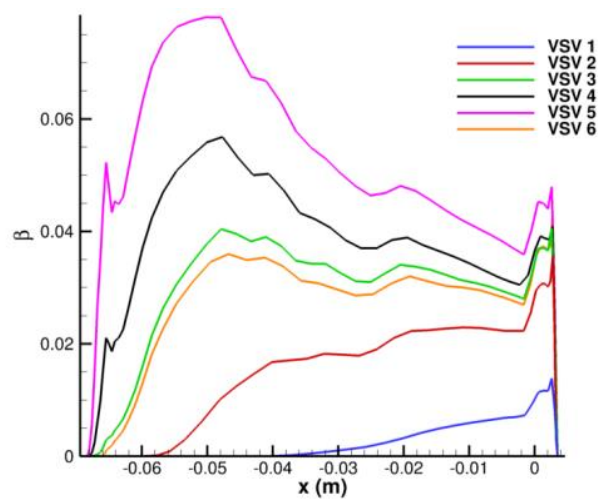

(b) Droplet catch efficiency (VSVs)

Fig. 18 Numerical results for droplet trajectory, $V=50 \mathrm{~m} / \mathrm{s}$ and $\mathrm{VSV}$ incidence $=10^{\circ}$

On Fig. 19, ice accretion shapes for two test cases are compared with IGLOO2D numerical results ("predictor" and "corrector" approach). For test condition 8, the "predictor" approach doesn't predict correctly the ice shape, and the "corrector" approach seems to retrieve correctly the width and the extent in the chord wise direction. This result is probably due to the fact that the size of the ice shape is not negligible compared to the vane dimension, and that modification of the aerodynamic profile has to be considered during the ice accretion calculation. For test condition 3 , the predictor and corrector results are rather similar. Even if the triangular ice shape is rather correctly reproduced, the predicted width of the ice is lower than the experimental results.

In order to improve the results, a multi-step approach was tested. Example of results are presented on Fig. 20. For test condition 8, the agreement with experimental shape seems to be not so good. The spearhead shape is not reproduced, and the ice shape width seems to constantly widen with the time. Regarding the dimension of the ice shape, the predicted shape width is lower, but its chord-wise extent remains comparable to the corrector and experimental results. For test condition 3, the shape of the ice is slightly different, as the simulation do not reproduce exactly the triangular shape, but rather predict a two-horn shape. However, the agreement on the width of the ice is better, which is an important feature for the calculation of ice obstruction.

At this stage, the predictor-corrector approach seems to predict more correctly the ice accretion shape for selected test cases, but for the glaze conditions, it underestimates the obstruction phenomena. For engine application, this characteristic is a key parameter for the engine operability assessment, and must be correctly modeled. The multi-step approach seems to better capture the obstruction, but it doesn't capture the exact ice shape. Improvement of the methodology is required, and some best practices has to be developed (number of time steps, spatial discretization of the profile and ice shape...). Still, at this stage, it seems to be the most promising approach for calculation on engine application.

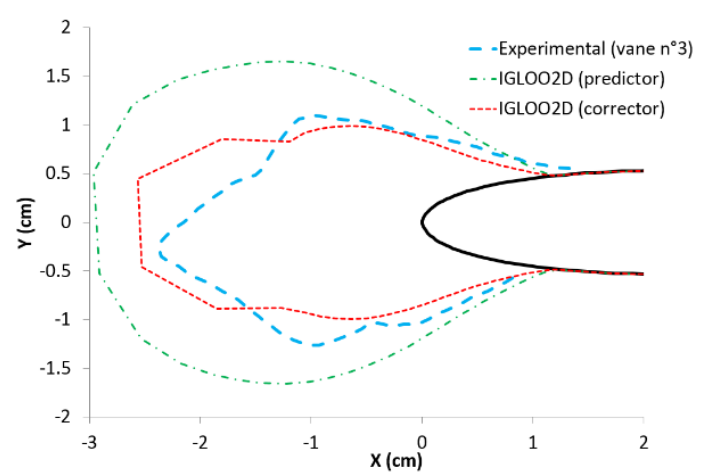

a) Test condition 8

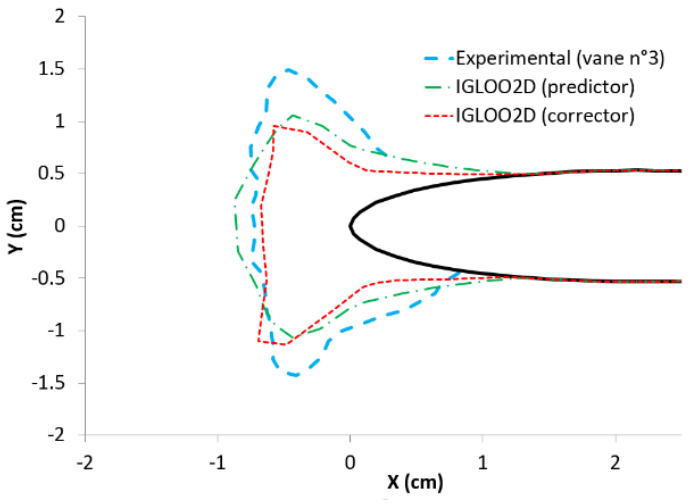

b) Test condition 3

Fig. 19 Numerical results for ice accretion on vanes (predictor and corrector approach) 


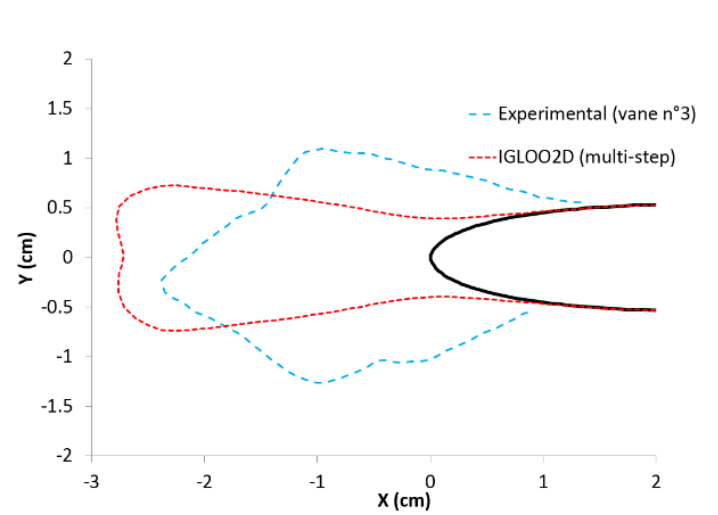

a) Test condition 8

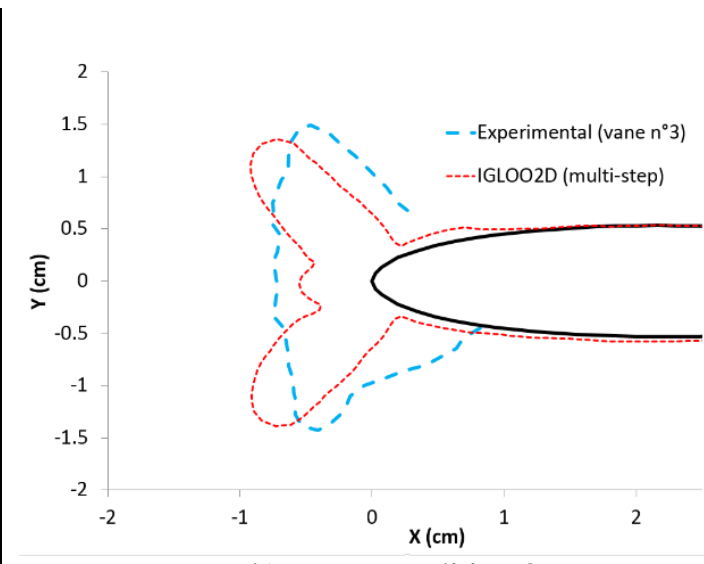

b) Test condition 3

Fig. 20 Numerical results for ice accretion on vanes (multi-step approach)

\section{Conclusion}

A comprehensive database for the validation of anti-icing numerical tools had been acquired through Icing Wind Tunnel testing. The test article is representative of an engine inlet, with two stator stages, the upstream one being antiiced with a thermal system. Main conclusions were:

1. A shadow effect for the droplet trajectory was observed for test cases with the two stator vanes aligned. This elements is interesting to assess water droplets trajectory solver applied to engine environment.

2. Runback water was observed on the anti-iced vanes surface as water rivulets and/or beads, depending on the test conditions or power setting. Runback water accumulates at the anti-iced vanes trailing edge under the shape of water reservoirs.

3. Ice accretion shapes from re-emitted droplets have a rather irregular thickness along the span wise direction, which could be explained by the water release from non-uniformly distributed reservoirs.

4. The quantity of ice formed by re-emitted droplets impingement vary significantly with the heat power. For glaze ice test conditions, it can have a major impact on the air flow blockage.

Regarding numerical results, this first work was focused on the modeling of droplet trajectory and ice accretion on the first vane stage, without heating. Following observation were pointed out:

1. The trajectory calculation reproduces the shadowing effect experimentally observed (droplet impingement on the VSV pressure side and not on the leading edge).

2. One-step (predictor) ice accretion calculation seems not to be adapted for ice accretion calculation on small engine components, as the aerodynamic profile will be very quickly modified.

3. Iterative approach like predictor-corrector allows to reproduce the ice shape, but for glaze condition, it fails to reproduce the obstruction of the air flow. Multi-step approach seems to be the most promising way to correctly capture this feature, but additional work is required to improve the agreement with the ice shape.

Further work will be dedicated to extent the post-processing of the experimental database, especially regarding the behavior of the runback water and the link with test conditions. Modelling of the ice accretion phenomena will be improved, with a focus on multi-stepping approach. Multi-stepping methodology is today available for 2D tools, but to address industrial test cases, it is necessary to develop same approach for 3D tools.

\section{Acknowledgments}

The research leading to these results has received funding from the European Union Seventh Framework Programme (FP7/2007-2013) under grant agreement $n^{\circ} 605180$.

\section{References}


[1] G. Gomez de Segura Solay, E. Radenac, R. Chauvin and C. Laurent, "Simulations of ice accretion, runback and droplet re-emission in a multi-stage model of aeronautical engine," in 8th AIAA Atmospheric and Space Environments Conference, AIAA AVIATION Forum, (AIAA 2016-4350), 2016.

[2] C. Laurent, E. Radenac, D. B. G. Linassier, P. Berthoumieu, J. Senoner and P. Villedieu, "Modeling of drop reemission on a small scale rotating Fan model: comparison between experimental and numerical results," in 7TH EUROPEAN CONFERENCE FOR AERONAUTICS AND SPACE SCIENCES (EUCASS), EUCASS2017517, 2017.

[3] K. Al-Khalil, C. Horvath, D. Miller and W. Wright, "Validation of NASA Thermal Ice Protection Computer Codes Part 3: The validation of Antice," in AIAA-97-0051, 2001.

[4] M. Papadakis, S. Wong, H. Yeong, S. Wong and G. VU, "Icing Tunnel experiments with Hot Air Anti-Icing Systems," in 46th AIAA Aeropsace Sciences Meeting and Exhibit, Reno, Nevada, 2008.

[5] S. Lee, L. E, A. Broeren and M. Bragg, "Simulation of Icing on a Cascade of Stator Blades," in 44th AIAA Aerospace Sciences Meeting and Exhibit, Reno, Nevada, 2006.

[6] M. Ramezanizadeh, S. M. H. Pouryoussefi, M. Mirzaei and S. G. Pouryoussefi, "Experimental Investigation on the Ice Accretion Effects of Airplane Compressor Cascade of Stator Blades on the Aerodynamic Coefficients," Journal of Applied Fluid Mechanics, vol. 6, no. 2, pp. 167-175, 2013.

[7] G. L. Shires and G. E. Munns, "The Icing of Compressor Blades and their Protection by Surface Heating," Aeronautical Research Council Reports and Memoranda, 1958.

[8] W. Dong, J. Zhu and Q. and Zhao, "Numerical Simulation Analysis of a Guide Vane hot Air Anti-icing System," in 42nd AIAA Thermophysics Conference, Honolulu, Hawaii, 2011.

[9] W. Dong, Y. Chen, J. Zhu and Z. Zhou, "Experimental study on hot lubricating oil anti-icing system of aeroengine strut," in Proceedings of ASME Turbo Expo 2014: Turbine Technical Conference and Exposition GT2014, Düsseldorf, Germany, 2014.

[10] V. Tatar and H. Aras, "An investigation on an anti-ice static vane of a gas turbine engine," Applied Thermal Engineering, vol. 110, no. 5, pp. 1038-1050, 2017.

[11] A. Refloch, B. Courbet, A. Murrone, P. Villedieu, C. Laurent, P. Gilbank, J. Troyes, L. Tessé, G. Chaineray, J. Dargaud, E. Quémerais and F. Vuillot, "CEDRE software," AerospaceLab Journal, vol. 2, 2011.

[12] P. Trontin, A. Kontogiannis, G. Blanchard and P. Villedieu, "Description and assessment of the new ONERA 2D icing suite IGLOO2D," in 9th AIAA Atmospheric and Space Environments Conference, Denver, USA, 2017. 
2018-06-30

\title{
Experimental characterization of anti-icing system and accretion of re-emitted droplets on turbojet engine blades
}

\author{
Linassier, Guillaume
}

AIAA

Linassier G, Balland M, Pervier $\mathrm{H}$, et al., Experimental characterization of anti-icing system and accretion of re-emitted droplets on turbojet engine blades, Proceedings of the 2018 Atmospheric and Space Environments Conference, AIAA Aviation Forum, 25-29 June 2018, Atlanta, USA, Paper number AIAA 2018-3657

http://dx.doi.org/10.2514/6.2018-3657

Downloaded from Cranfield Library Services E-Repository 